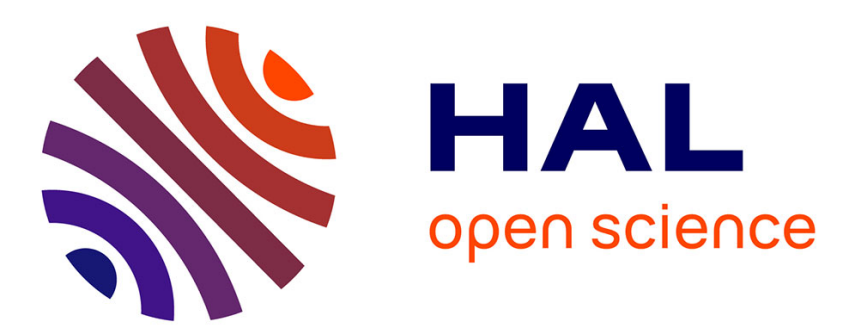

\title{
Erosion resistance and adhesion of composite metal/ceramic coatings produced by plasma spraying
}

D. Ramm, I. Hutchings, T. Clyne

\section{To cite this version:}

D. Ramm, I. Hutchings, T. Clyne. Erosion resistance and adhesion of composite metal/ceramic coatings produced by plasma spraying. Journal de Physique IV Proceedings, 1993, 03 (C7), pp.C7913-C7-919. 10.1051/jp4:19937141 . jpa-00251763

\section{HAL Id: jpa-00251763 https://hal.science/jpa-00251763}

Submitted on 1 Jan 1993

HAL is a multi-disciplinary open access archive for the deposit and dissemination of scientific research documents, whether they are published or not. The documents may come from teaching and research institutions in France or abroad, or from public or private research centers.
L'archive ouverte pluridisciplinaire HAL, est destinée au dépôt et à la diffusion de documents scientifiques de niveau recherche, publiés ou non, émanant des établissements d'enseignement et de recherche français ou étrangers, des laboratoires publics ou privés. 


\title{
Erosion resistance and adhesion of composite metal/ceramic coatings produced by plasma spraying
}

\author{
D.A.J. RAMM, I.M. HUTCHINGS and T.W. CLYNE \\ Department of Materials Science and Metallurgy, University of Cambridge, Pembroke Street, Cambridge, \\ U.K.
}

\begin{abstract}
Ceramic coatings can exhibit greater erosion resistance than most metallic coatings. Such coatings are conveniently produced by thermal spraying. Unfortunately, thermally sprayed ceramic coatings often exhibit poor adhesion, partly as a consequence of the development of residual stresses during spraying and subsequent cooling. Composite coatings have been studied using aluminium/alumina deposits on steel substrates. The incorporation of ceramics within a ductile matrix has potential for sharply reducing the erosive wear at high erodent impact angles, whilst retaining the good erosion resistance of ceramics at low angles. It is shown that the proportion of metal and ceramic at the free surface can be specified so as to optimise the erosion resistance. Experiments have also been carried out on the resistance of the coatings to debonding during four-point bending of the coated substrate. Progress is being made towards the tailoring of composition profiles in graded coatings so as to optimise the combination of erosion resistance and adhesion.
\end{abstract}

\section{Introduction}

Thermal spraying techniques are widely used to produce relatively thick ceramic coatings. Of specific interest are the High Velocity Oxy Fuel (HVOF) and Plasma Spraying (Air Plasma Spraying (APS) and Vacuum Plasma Spraying (VPS)) techniques. These have been described in considerable depth by several authors ${ }^{1-4}$. As with all thermal spraying processes, a consumable coating material is fed to a spray gun, raised in temperature and then projected in droplet/particulate form onto a substrate. The density and bond strength of the coating is dependent upon the material sprayed, the particle impact velocity, particle temperature and surface preparation.

Although the mechanisms of local coating adhesion are well established ${ }^{1,4,5}$, ranging from mechanical keying to chemical bonding, the macroscopic adhesion of plasma sprayed coatings is strongly influenced by residual stresses formed during spraying ${ }^{6}$. Mechanisms of residual stress generation have been proposed by Kuroda and Clyne ${ }^{7}$. The two major contributions to residual stress generation are quenching stresses and differential thermal contraction ${ }^{8,9}$. Quenching stresses are produced within splats as they cool to the temperature of the substrate material, the origin of the stress being the constraint of the underlying solid on the thermal contraction of the splats ${ }^{7}$. During subsequent heating and cooling of the substrate and deposit, large mismatches between the Coefficient of Thermal Expansion (CTE) of the two materials can result in the generation of large stresses. For ceramic coatings on a metallic substrate, these often result in the spallation of coatings ${ }^{7}$.

Article published online by EDP Sciences and available at http://dx.doi.org/10.1051/jp4:19937141 
Erosion is caused by the impact of hard particles, carried by a fluid stream, onto a material surface. In most materials erosion behaviour can be categorised as being either brittle or ductile in nature ${ }^{10}$. The major differentiating characteristic of the two types of erosion mechanism is the dependence of erosion rate on impact angle i.e. the angle between the moving erodent particles and the material surface ${ }^{11}$. There is general agreement that maximum erosion occurs at a low angle (about $30^{\circ}$ for ductile materials and at $90^{\circ}$ (normal impact) for brittle materials ${ }^{11}$. Figure 1 shows a schematic plot of the expected variation in erosion behaviour with impact angle. Most applications involve low impact angles, at which ceramics resist erosion more effectively.

It should be noted, however, that plasma sprayed coatings often differ significantly in microstructure from the corresponding bulk material. The structure of plasma sprayed coatings consists of many overlapped lenticular splats which conform, more or less, to the morphology of the underlying substrate or previous splat. The structure of a plasma sprayed composite coating of aluminium/alumina is presented in Fig 2. The microstructure of plasma sprayed coatings has been covered in detail by McPherson ${ }^{12,3}$. Although plasma sprayed coatings are anisotropic, they tend to exhibit the same dependence of erosion rate on impact angle as bulk metals and ceramics ${ }^{14}$. However both Kingswell ${ }^{15}$ and Zhang ${ }^{16}$ have noted that the erosion mechanisms in plasma sprayed alumina differ from those in bulk sintered alumina.

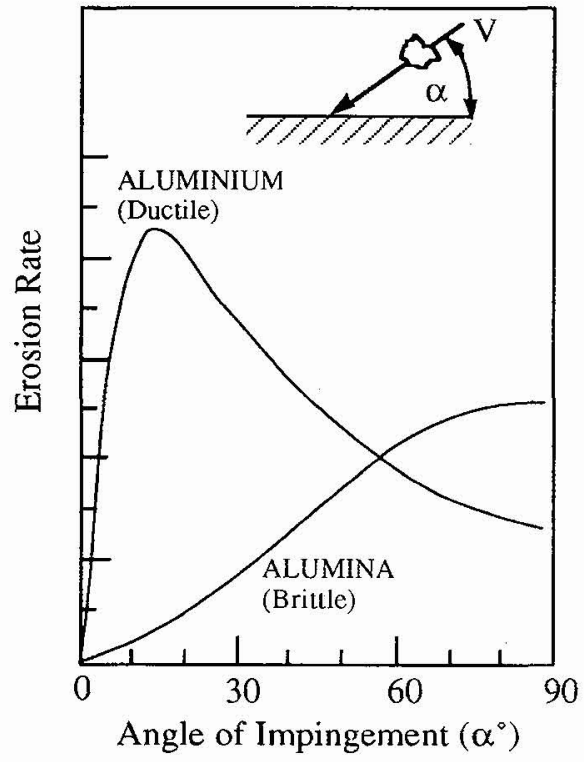

Figure 1;-The Expected Variation of Erosion Rate with Particle Impact Angle Characteristic of (a) Ductile Metals and (b) Brittle Materials

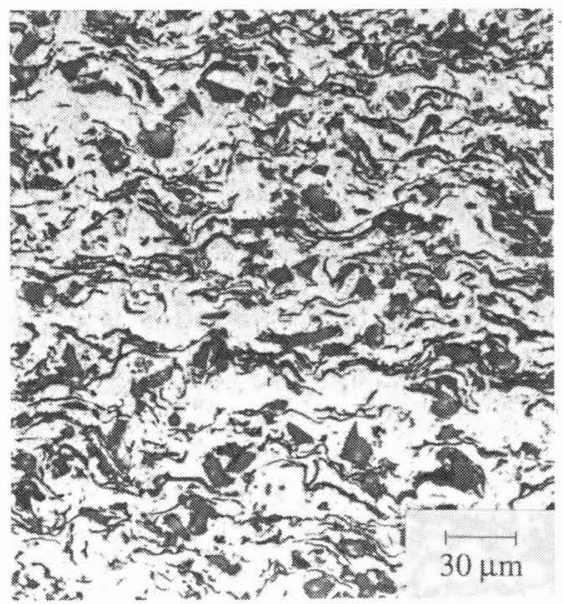

Figure 2;- Microstructure of Vacuum Plasma Sprayed Aluminium/Alumina Composites $(\mathrm{Vf}=50 \%)$

Erosion of bulk ceramics generally occurs by a number of fracture mechanisms ${ }^{17,}{ }^{18}$. During particle impact upon a ceramic surface, median and radial cracks develop at the impact site ${ }^{19}$. Upon rebound of the particle i.e. unloading of the impact site, lateral cracks develop parallel to the surface and finally curve and propagate towards the surface, leading to chipping and loss of material. Erosion in plasma sprayed ceramics has been attributed to the failure of individual splat boundaries. Although surface cracks have been seen to form in VPS coatings, similar to behaviour in sintered ceramics, propagation from one splat to another is limited. Subsurface damage of VPS alumina involves neither radial nor median cracks. Instead, cracks more similar to lateral fractures 
develop around impressions, in which a consolidated region immediately beneath the fracture is attributed to splat debonding ${ }^{20}$. As inter-splat bonding is increased, the damage mechanisms start to resemble those observed in bulk ceramics.

Composite coatings can in principle be produced so as to provide a compromise between the requirements of good erosion resistance and good deposit adhesion. In the current work, a preliminary report is given on the use of composite coatings designed to combine good adhesion with good erosion resistance.

\section{Experimental Procedures}

Alumina coatings were produced by each of the three major thermal spraying techniques, HVOF APS and VPS. Coatings were spayed onto mild steel substrates using Plasmalloy alumina powder for the HVOF system and Abrasive Developments White Alumina for both of the Plasma Spraying systems. For HVOF spraying a Miller Top Gun system was used. APS was conducted on a Metco 3M gun, whilst VPS alumina coatings were deposited using a Plasma Technik Plasma Spraying Unit with $40 \mathrm{KW}$ PTF4-V plasma gun. Basic spraying conditions are presented in Table I with porosity values for each of the ceramic coatings. Porosity measurements were determined by densitometry using a Sartorius hydrostatic balance.

\begin{tabular}{|c|c|c|c|c|c|c|}
\cline { 2 - 7 } \multicolumn{1}{c|}{} & $\begin{array}{c}\text { Operating } \\
\text { Pressure } \\
(\mathrm{mbar})\end{array}$ & $\begin{array}{c}\text { Torch } \\
\text { Power } \\
(\mathrm{kW})\end{array}$ & $\begin{array}{c}\text { Powder } \\
\text { Feed Rate } \\
(\mathrm{g} / \mathrm{s})\end{array}$ & $\begin{array}{c}\text { Standoff } \\
\text { Distance } \\
(\mathrm{mm})\end{array}$ & $\begin{array}{c}\text { Estimated } \\
\text { Part. Vel. } \\
(\mathrm{m} / \mathrm{s})\end{array}$ & $\begin{array}{c}\text { Measured } \\
\text { Porosity } \\
(\%)\end{array}$ \\
\hline VPS & 250 & 45 & 1.5 & 280 & 500 & 4.6 \\
\hline APS & 1000 & 45 & 1.5 & 160 & 300 & 10.8 \\
\hline HVOF & 1000 & 220 & 0.8 & 150 & 800 & 0.9 \\
\hline
\end{tabular}

Table I:- Thermal Spraying Conditions and Porosity of Alumina Coatings

Composite plasma sprayed coatings were prepared from commercial alumina (Abrasive Developments White Alumina) and aluminium 6061 (Metalloys) plasma spray powders. The substrates used for the experiments were mild steel plates, $140 \mathrm{~mm} \times 25 \mathrm{~mm} \times 3.2 \mathrm{~mm}$ in size. Substrate surfaces were prepared for plasma spraying by grit blasting with alumina followed by cleaning with inhibisol. Coatings were sprayed using a Plasma Technik Vacuum Plasma Spraying (VPS) unit with $40 \mathrm{~kW}$ PTF4-V plasma gun. A PT Twin-10V powder feed was used to convey the two powders into the plasma gun nozzle: Coatings of $50 \%$ and $100 \%$ alumina were deposited, plus coatings of $100 \%$ aluminium.

Erosive wear rates were measured using the gas blast apparatus described by Hutchings et $\mathrm{al}^{21}$. Particle impact velocity was measured by the double rotating disc method of Ruff and Ives ${ }^{22}$. Erosion testing was carried out using the conditions shown in Table II. It was found that the erosive wear of coatings was linearly related to the mass of erodent which had struck the surface, so the erosion rate results are quoted as mass loss from the specimen per unit mass of impacting particles.

\begin{tabular}{|c||c|}
\hline Impact Angle & $20^{\circ} \& 90^{\circ}$ \\
\hline Impact Velocity & $50 \mathrm{~m} / \mathrm{s}$ \\
\hline Erodent & Angular Silica (mean diameter $200 \mu \mathrm{m}$ ) \\
\hline Nozzle & $300 \mathrm{~mm}$ long, Internal Diameter $6.3 \mathrm{~mm}$ \\
\hline Specimen Position & $15 \mathrm{~mm}$ from end of nozzle \\
\hline
\end{tabular}

Table II:- Erosion Testing Conditions 
Adhesion testing was conducted using the four point bend delamination test ${ }^{23}$. The test involves four point bending under displacement control. Analysis of load/displacement data ${ }^{24}$ allows evaluation of the critical strain energy release rate of the interface.

The Young's Moduli of plasma sprayed coatings were determined using a Grindo Sonic Mk5 'resonant frequency measurement device.

\section{Results and Discussion}

Table I presents results of porosity measurements for each of the three thermal spraying techniques investigated, High Velocity Oxy-Fuel, Air Plasma Spraying and Vaccum Plasma Spraying (HVOF, APS and VPS). Of the two plasma spraying techniques, VPS alumina coatings exhibited lower porosity content than the corresponding APS alumina. This is a result of fundamental differences between APS and VPS. Air entrapment within individual pores is common in APS, as is rapid cooling of molten material in flight, resulting in partial solidification of splats prior to impact ${ }^{13}$. Another major factor influencing porosity content is particle velocity (Table I). Particle velocity in VPS is considerably greater than that of APS due to the lower operating pressures. As chamber pressure is further reduced particle velocity, and therefore coating density, increase correspondingly. Each of the aforementioned conditions results in different forms of porosity. Retained gases within splats result in spherical porosity within the splats, whereas early solidification or incomplete melting results in irregular pores $(3-10 \mu \mathrm{m})$ due to incomplete filling of interstices between previously deposited particles. Such porosity is also strongly affected by particle velocity as are fine planar pores $(\sim 0.1 \mu \mathrm{m})$, observed between individual splats, and a feature of incomplete contact between lamellae. HVOF coatings exhibit extremely low porosity due to very high impact velocities. However, although overall porosity measurements were made, it is unclear as to the proportion of each type of porosity present in each of the coatings.

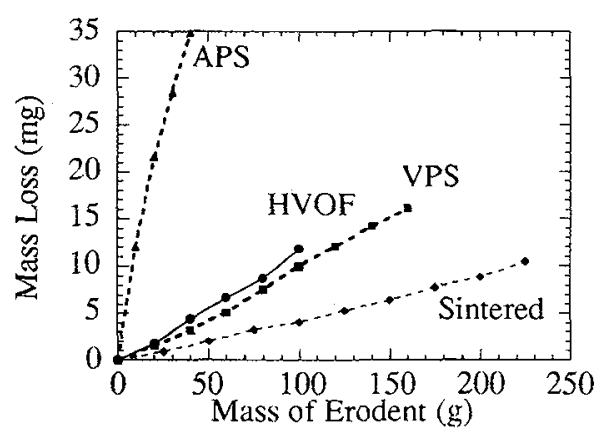

Figure 3:- Erosion Resistance of Thermally Sprayed Alumina Coatings $\left(\alpha=90^{\circ}\right)$

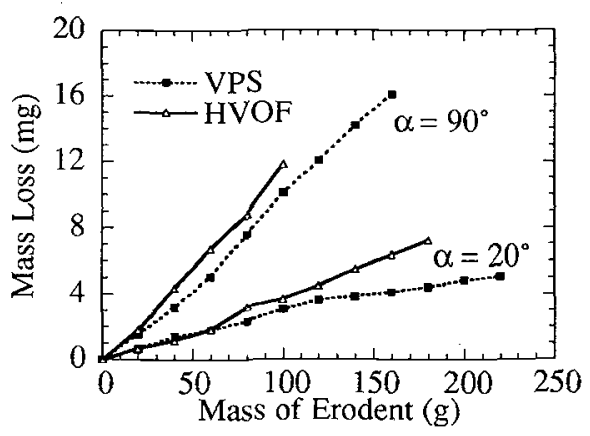

Figure 4:- Erosion Resistance of HVOF and VPS Alumina Coatings at Impact angles of $20^{\circ}$ and $90^{\circ}$

Figure 3 shows a comparison of erosion resistance between each of the thermally sprayed alumina coatings, together with bulk sintered alumina. Of the thermally sprayed aluminas, VPS and HVOF give greater erosion resistance at high impact angles $\left(\alpha=90^{\circ}\right)$ than APS alumina. The steady state erosion rate of APS alumina is approximately eight times greater than that of either HVOF or VPS alumina. This is principally due to the low impact velocity of APS and rapid 
cooling of molten material; not only does it affect the porosity content of the coating, but the instersplat bond strength i.e.cohesion of coating. Closer examination of HVOF and VPS alumina (Figure 4), under erosion conditions at normal and incident angles, suggests that the erosion performance of VPS alumina is marginally superior to that of HVOF. Although VPS displays lower particle impact velocities than HVOF, higher core temperatures (16000K compared with $3200 \mathrm{~K}$ ) and substrate temperatures of VPS promote greater coating cohesion, resulting in greater erosion resistance. It should be noted that greater flame and substrate temperature are not entirely beneficial to the deposition of alumina coatings upon metallic substrates. Large mismatches in Coefficient of Thermal Expansivity (CTE) between substrate and deposit often results in spallation of coatings when cooling from the higher temperatures associated with VPS. Substrate temperature during VPS was about $800 \mathrm{~K}$ compared with $400 \mathrm{~K}$ for $\mathrm{HVOF}$.

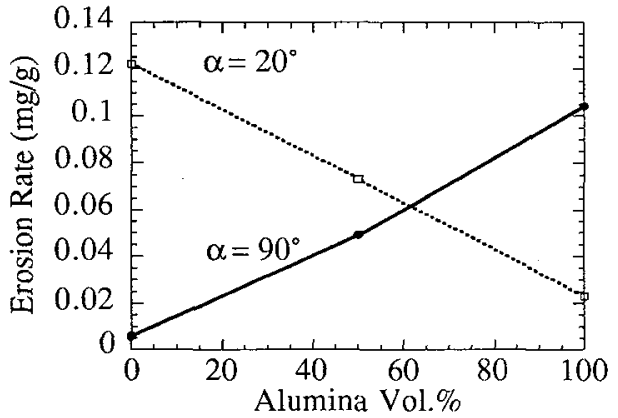

Figure 5;-Variation in Erosion Rate with Composite Volume Fraction, for Impact angles of $20^{\circ}$ and $90^{\circ}$.

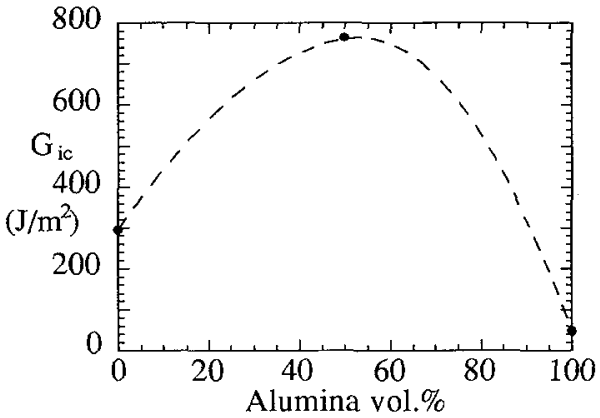

Figure 6;- Variation of Coating/Substrate Fracture Toughness $\left(\mathrm{G}_{\mathrm{ic}}\right)$ with Composite Volume Fraction.

As displayed in Figure 1, erosion behaviour varies strongly with coating hardness. Maximum erosion rates for Aluminium coatings occur at low angles of particle impact $\left(15-30^{\circ}\right)$, whereas maximum erosion for Alumina coatings is at normal impact $\left(90^{\circ}\right)$. Figure 5 demonstrates the effect of a composition on erosion the resistance of composite coatings, for impingement angles of $20^{\circ}$ and $90^{\circ}$. Although only a few data points have as yet been determined, the plot suggests that the erosion properties of $\mathrm{Al} / \mathrm{Al}_{2} \mathrm{O}_{3}$ are intermediate between those of the parent materials. In fact, the plot suggests an approximately linear variation in erosion rate between the single phase coatings.

Of particular interest are high volume fraction compositions, between $80-95 \% \mathrm{Al}_{2} \mathrm{O}_{3}$. The addition of a small proportion of aluminium to an alumina coating may improve the erosion resistance at normal impact without having too detrimental an effect on impact at low angles. Impact of molten alumina particles upon a substrate, followed by immediate cooling of the splats, causes large stresses in the splats, referred to as quenching stresses. Relaxation of these stresses occurs by microcracking of the splat, alternative stress relief mechanisms such as yielding or creep being inappropriate for ceramic coatings. These microstructural flaws are believed to reduce the erosion resistance, aiding the chipping mechanism by which VPS ceramic coatings are eroded. The introduction of a ductile metallic phase could encourage stress relaxation by yielding or creep of the underlying and surrounding metallic phase.

The use of composites also has a strong effect upon the adhesion of plasma sprayed coatings. Figure 6 presents critical interfacial strain energy release rate data (fracture toughness). Both 100 $\%$ aluminium and $100 \%$ alumina appear to exhibit poor adhesion. However, failure of the aluminium coating was within the deposit, a fine layer of aluminium being strongly adhered to the 
substrate surface. Therefore failure was a result of poor cohesion of the aluminium deposit as opposed to poor adhesion. This may be a result of fines (debris and particulate within the chamber) being deposited between spray passes. Poor adhesion of the alumina coating can be attributed to poor cohesion between metal substrate and ceramic deposit, and the presence of large residual stresses due to a large mismatch in CTE between substrate and deposit. The macroscopic adhesion of the composite coating may also be strongly influenced by CTE, as the mild steel substrate and composite coating have similar values of CTE (approximately $13 \mathrm{MK}^{-1}$ ), reducing residual stresses and resulting in apparently good adhesion.

Erosion and adhesion results suggest that the compositional requirements at the free surface and at the substrate/deposit interface differ strongly. Compromises can be achieved by the use of composite coatings, although a more desirable solution might be the use of functionally gradient coatings, in which there is a compositional gradient from interface to free surface.

\section{Conclusions}

1) Thermal Spraying Processes have been used to fabricate ceramic and metal/ceramic composite coatings.

2) Although HVOF spraying produces significantly denser coatings, VPS coatings exhibit higher erosion resistance than both APS and HVOF.

3) Composite coatings give good erosion resistance over a range of angles and improved adhesion resistance.

\section{Acknowledgements}

The authors are grateful to Sue Dunkerton, Andy Sturgeon and David Harvey, of The Welding Institute, Abingdon, for their financial support and production of HVOF sprayed specimens tested during this work.

\section{References}

1. I. A. Fisher, Variables Influencing the Characteristics of Plasma-Sprayed Coatings, Int. Met. Rev., 17 (1972), pp. 117-129.

2. J. H. Zaat, A Quarter of a Céntury of Plasma Spraying, Ann. Rev. Mat. Sci., 13 (1983), pp. 942.

3. A. R. Nicoll et al., Thermal Spray Coatings for High Temperature Application, Surf.Eng., 1(1) (1985), pp. 59-71.

4. H. Herman, Plasma Spray Deposition Processes, MRS Bulletin, (Dec.) (1988), pp. 60-67.

5. P. E. Chandler, Improving the Bonding of Plasma Sprayed Coatings, C.E.G.B. (Technology Planning and Research Division), Marchwood Engineering Laboratories, United Kingdom, 1985.

6. S. J. Howard, The Interfacial Toughness of Plasma Sprayed Coatings on Titanium Alloys, PhD., University of Cambridge (1993).

7. S. Kuroda and T. W. Clyne, The Quenching Stress in Thermally Sprayed Coatings, Thin Solid Films, 200 (1991), pp. 49-66.

8. S. C. Gill and T. W. Clyne, Stress Distributions and Material Response in Thermal Spraying of Metallic and Ceramic Deposits, Met. Trans., 21B (1990), pp. 377-385.

9. S. C. Gill and T. W. Clyne, Modelling of the Generation of Residual stress during Thermal Spraying of Ceramic Coatings, in Seventh CIMTEC World Ceramic Congress (1990), Montecatini, Italy, P. Vincinzini, Elsevier, pp. 339-352.

10. G. P. Tilly, Erosion Caused by Impact of Solid Particles, Treatise on Materials Science and Technology, 13 (1979), pp. 287-319.

11. I. M. Hutchings, Recent Advances in the Understanding of Solid Particle Erosion., Mecanique Materiaux Electricite, 365 (1980), pp. 185-192.

12. R. McPherson, The Relationship between the Mechanism of Formation, Microstructure and Properties of Plasma-sprayed Coatings, Thin Solid Films, 83 (1981), pp. 297-310. 
13. R. McPherson, A Review of Microstructure and Properties of Plasma Sprayed Ceramic Coatings, Surface and Coatings Technology, 39/40 (1989), pp. 173-181.

14. J. G. Murphy, H. W. King and M. L. Taylor, Particulate Erosion of Zirconia-Alumina Plasma Sprayed Coatings I:Ceramic Coating Erosion Mechanism, The Canadian Ceramic Society, 56 (1987), pp. 26-32.

15. R. Kingswell, K. T. Scott and S. Bull, Erosion Behaviour of Plasma Sprayed Alumina Coatings, in 2nd Plasma Technik Symposium (1991), Lucerne, Switzerland, pp. 367-377

16. X. X. Zhang, I. M. Hutchings and T. W. Clyne, The Effect of Deposition Conditions on the Erosive Wear Resistnce of Plasma Sprayed Alumina Coatings, in 2nd European Conference on Advanced Materials and Processes (1991), Euromat 91, pp.

17. B. R. Lawn and M. V. Swain, Microfracture beneath Point Indentations in Brittle Solids, J.Mat.Sci., 10 (1975), pp. 113-122.

18. B. R. Lawn and D. B. Marshall, Hardness,Toughness and Brittleness: An Indentation Analysis, J.Am.Ceram.Soc., 62 (1979), pp. 347-350.

19. B. R. Lawn and R. Wilshaw, Review, Indentation Fracture: Principles and Applications, J.Mat.Sci., 10 (1975), pp. 1049-1091.

20. X. X. Zhang, The Erosion of Plasma Sprayed Alumina Coatings by Solid Particle Impact., PhD., University of Cambridge (1991).

21. I. M. Hutchings, D. W. T. Deuchar and A. H. Muhr, Erosion of Unfilled Elastomers by Solid Particle Impact, J.Mat.Sci., 22 (1987), pp. 4071-4076.

22. A. W. Ruff and L. K. Ives, Measurement of Solid Particle Velocity in Erosive Wear, Wear, 35 (1974), pp. 195-199.

23. P. G. Charalambides et al., A Test Specimen for Determining the Fracture Resistance of Bimaterial Interfaces, J.App.Mech.(Trans.ASME), 56 (1989), pp. 77-82.

24. S. J. Howard, A. J. Phillipps and T. W. Clyne, The Interpretation of Data from Four-Point Bend Testing to Measure Interfacial Fracture Toughness, Composites, (1992), pp. 